\title{
Characterization and clinical evaluation of microsatellite instability and loss of heterozygosity in tumor-related genes in gastric cancer
}

\author{
XUEYUN HUO ${ }^{1,2}$, XIAOQIN XIAO ${ }^{1,2}$, SHUANGYUE ZHANG ${ }^{1,2}$, XIAOYAN DU $^{1,2}$, \\ CHANGLONG LI ${ }^{1,2}$, ZHIGANG BAI $^{2-4 *}$ and ZHENWEN CHEN ${ }^{1,2 *}$
}

${ }^{1}$ School of Basic Medical Sciences, Capital Medical University; ${ }^{2}$ Tumor Model Laboratory, Beijing

Key Laboratory of Cancer Invasion and Metastasis Research, Beijing 100069; ${ }^{3}$ Department of General

Surgery, Beijing Friendship Hospital, Capital Medical University; ${ }^{4}$ Department of General Surgery,

National Clinical Research Center for Digestive Diseases, Beijing 100050, P.R. China

Received June 12, 2020; Accepted February 10, 2021

DOI: $10.3892 / \mathrm{ol} .2021 .12691$

\begin{abstract}
Microsatellite instability (MSI) detection is widely used in the diagnosis and prognosis evaluation of colorectal cancer. However, for gastric cancer (GC), there is no standard panel of microsatellites (MSs) used in clinical guidance. The present study aimed to identify useful predictors of the clinical features and for the prognosis of GC, based on an investigation of MSI and loss of heterozygosity $(\mathrm{LOH})$ in tumor-related genes. First, from 20 tumor-related genes which were proven to be important to the development of GC, 91 MSs were identified, and PCR amplification, short tandem repeat scanning analysis and TA clone sequencing were used to analyze MSI and $\mathrm{LOH}$ in the first set of $90 \mathrm{GC}$ samples. Subsequently, the same method was used to detect the MSI/LOH of the optimized loci in the second set of $136 \mathrm{GC}$ samples. MSI/LOH in the mismatch repair genes was highly consistent with that in oncogenes and tumor suppressor genes, respectively. The length of the core sequence was a main factor for the MSI/LOH rate. The MSI of 12 single loci was significantly associated with lymph node metastasis. The MSI in TP53-1 and the LOH in MGMT-10 were significantly associated with early stages of tumor infiltration depth. The LOH in MGMT-10, PTN-2 and MCC-17 was significantly associated with TNM stage. The
\end{abstract}

Correspondence to: Professor Zhenwen Chen, School of Basic Medical Sciences, Capital Medical University, 10 Xitoutiao, Youwai Street, Beijing 100069, P.R. China

E-mail: czwen@ccmu.edu.cn

Dr Zhigang Bai, Department of General Surgery, Beijing Friendship Hospital, Capital Medical University, Beijing 100050, P.R. China E-mail: bai_zhg@163.com

${ }^{*}$ Contributed equally

Key words: microsatellite stability, loss of heterozygosity, gastric cancer, prognosis, tumor-related genes
LOH in TP53-1 and ERBB2-12 was associated with adenocarcinoma. The MSI/LOH in 6 single loci of 5 tumor-related genes was associated with poor prognosis of GC. The present study demonstrated that the MSI/LOH of loci in tumor-associated genes was associated with 4 clinicopathological characteristics and outcomes of GC. These results may provide potential specific biomarkers for the clinical prediction and treatment of GC.

\section{Introduction}

According to the global cancer statistics of 2018, gastric cancer (GC) is the fifth most common type of cancer $(1,033,701$ new cases) and the third leading cause of cancer-associated mortality (782,685 deaths) worldwide (1). The incidence rate of GC has been declining in North America and most Western European countries; however, the burden of GC remains high in Asia, Latin America, and Central and Eastern Europe (2). Notably, half of all cases of GC worldwide occur in East Asia (3). Despite the progress in the development of novel therapeutic approaches, the prognosis of GC remains poor, as the traditional histological subtypes cannot be used to determine the different prognoses and chemotherapeutic responses (4-6). Emerging data have suggested that GC is a complex and heterogenic disease. The underlying molecular and histopathological tumor features are responsible for the diverse outcomes and chemotherapeutic responses of patients (7-9). The genomic and molecular classification of GC have been addressed by The Cancer Genome Atlas and the Asian Cancer Research Group, both of which have indicated that microsatellite instability (MSI) GC is a separate subgroup of GC $(10,11)$.

MSI is a type of genetic instability, characterized by length alteration in the tandem repeat sequence, which is referred to as a microsatellite (MS) (12), is known as a hypermutable phenotype and occurs due to a defective DNA mismatch repair (MMR) system, with key MMR gene inactivations, such as germline mutations in mutS homolog 2 (MSH2) or mutL homolog 1 (MLH1) (13). At present, MSI detection is widely 
used in the screening of Lynch syndrome and the prognosis evaluation of colorectal cancer (CRC) using the Bethesda (B5) panel recommended by the American National Cancer Institute (14). However, Hause et al (15) identified MSI-positive tumors in 14 out of 18 cancer types, using 5,930 cancer exomes and the mutation-prone MS loci of different tumors were largely distinctive, indicating that loci that are stable in one type of cancer may be frequently altered in another. In GC, the association between MSI and clinical features remains ambiguous, which may be due to the arbitrary use of MS loci, which is mostly based on CRC studies to define MSI status in different studies, and these loci are not likely to be sufficient for making clinical decisions. Therefore, there is an urgent requirement to identify novel MS loci for the clinical guidance of GC $(11,16,17)$.

It is well-known that the alteration of tumor-related genes, such as the inactivation of tumor suppressor (TS) genes and the amplification of oncogenes, is a main factor in GC development $(18,19)$. On the other hand, MSs are frequently used as markers for the detection of loss of heterozygosity (LOH), which has been associated with GC progression (20). MSI and LOH status have been considered to be valuable and independent prognostic markers in patients with CRC (21).

The present study first focused on a wide range of MS loci located in GC-related genes, which were likely to be associated with GC development, and aimed to identify a panel of MS loci, which could be potential predictive biomarkers for clinical features and outcomes of GC.

\section{Materials and methods}

Enrolled patients. The present retrospective study comprised of patients with GC (226 specimens), who underwent surgical resection between March 2008 and November 2014, and in which normal adjacent mucosa and tumor tissues were collected. In addition, clinical information from the Clinical Data and Biobank Resource of Beijing Friendship Hospital (Beijing, China), was also collected for these patients. This has also been assessed and certified to meet the requirements of the China Human Genetic Resources Management Office and ISO certification 9001:2015. The inclusion criteria for patients were: i) Presence of a paired tissue sample (paired normal adjacent mucosa and tumor tissues); and ii) Complete or partial clinical information collected in the Clinical Data and Biobank Resource of Beijing Friendship Hospital (Beijing, China). The following exclusion criteria were used for patient recruitment: i) Does not have frozen tumor tissues or paired normal adjacent mucosa; ii) Does not have any clinical information; iii) Was not admitted between March 2008 and November 2014; iv) And the initial surgical treatment was not performed at Beijing Friendship Hospital (Beijing, China). The tumor and normal adjacent mucosa tissues were collected for research. To distinguish the normal adjacent mucosa from the tumor tissues, the normal tissues were first defined by its macroscopical character and then harvested by keeping a minimum distance of $5 \mathrm{~cm}$ from the tumor tissue. Histological classification was defined according to the World Health Organization guidelines (22). Detailed information of the patients is shown in Table I. As aforementioned, the samples and the clinical information were collected directly from the
Clinical Data and Biobank Resource of Beijing Friendship Hospital, and certain clinical information of a few patients were missing, due to the lack of routine detection, such as HP infection or other unknown reason. The Ethics Committee of Beijing Friendship Hospital (Beijing, China) approved the study proposal (approval. no. 2017-P2-013-03) and all patients involved in the study provided written informed consent. A total of 226 GC samples were defined as the validation set and a sub-group of 90 samples among the 226 GCs was defined as the training set.

DNA isolation. Total genomic DNA was isolated and purified from 226 tumor and normal adjacent tissues using a standard phenol-chloroform extraction and ethanol precipitation method, as previously described by Du et al (23). In addition, the quality of DNA was evaluated by measuring the A260/A280 ratio with a micro-volume spectrophotometer (NanoDrop 2000; Thermo Fisher Scientific, Inc.) and further assessed using 1.5\% agarose gel electrophoresis.

MS analysis. In total, 20 genes with mononucleotide (mono-), dinucleotide (di-), trinucleotide (tri-), tetranucleotide (tetra-), pentanucleotide (penta-) or compound (more than one type of repeat motif) MSs were selected for screening. Cancer-associated genes, including $A R I D I A, A P C, B A X$, $B R A F, C D K N 1 A, C D X 2, C T N N B 1, E R B B 2, E 2 F 4, M C C$, PTN, PTEN, PRR11, RUNX3, TGFBRII and TP53, which have been reported to be associated with GC in the literature, and MMR genes, including MSH2, MLH1, MGMT and $P M S 2$, were included in the present study (24-31). In total, $91 \mathrm{MS}$ loci were selected from the 5' untranslated region (UTR), intron, exon or 3'UTR of these 20 genes using the SSRHunter software (v1.3) (Li Qiang, Nanjing Agricultural University) and manual searching (Table SI), then primers for each selected MS were designed based on the flanking sequence using Primer Blast in the Pubmed website (https://www.ncbi.nlm.nih.gov/tools/primer-blast/index. cgi?LINK_LOC=BlastHome). Subsequently, the suitability of the designed primers was determined using PCR and the conditions were optimized. The B5 panel (BAT25, BAT26, D2S123, D5S346 and D17S250) which was used as the control to compare with the loci in tumor-related genes was also included in the present study . PCR was used to amplify these loci and short tandem repeat (STR) scanning (fluorescence capillary electrophoresis) was used for the detection of MSI, which were both performed on an ABI-3730XL DNA Analyzer system (Applied Biosystems; Thermo Fisher Scientific, Inc.), as previously described by Huo et al (32). Briefly, the PCR $(20 \mu \mathrm{l})$ was performed using a Taq DNA polymerase kit (cat. no. R001AM; Takara Bio, Inc.,) and included $2 \mu \mathrm{l} 10 \mathrm{X}$ buffer, $0.5 \mu \mathrm{mol} / 1$ of each primer (synthesized by Sangon Biotech Co., Ltd.), $125 \mu \mathrm{mol} / 1 \mathrm{dNTP}(4 \mathrm{X}), 1.0 \mathrm{U}$ Taq DNA polymerase, $1.5-2.5 \mathrm{mmol} / 1 \mathrm{MgCl}_{2}$ and $100 \mathrm{ng}$ template DNA. The following thermocycling conditions were used: Initial denaturation at $94^{\circ} \mathrm{C}$ for $5 \mathrm{~min}$; followed by 35 cycles of denaturation at $94^{\circ} \mathrm{C}$ for $30 \mathrm{sec}$, annealing at gradient temperatures for each MS for $30 \mathrm{sec}$ and extension at $72^{\circ} \mathrm{C}$ for $30 \mathrm{sec}$; and a final extension at $72^{\circ} \mathrm{C}$ for $5 \mathrm{~min}$.

A result was determined to be a MSI when the PCR product generated for the tumor sample exhibited at least one 
Table I. Association between MSI status detected using the Bethesda panel and clinicopathological characteristics in patients with GC.

\begin{tabular}{|c|c|c|c|c|}
\hline Clinicopathological characteristic & Number (\%) & MSI-H & MSI-L/MSS & P-value \\
\hline Mean age, years & $226(100)$ & 65.9 & 62.4 & 0.074 \\
\hline \multicolumn{5}{|l|}{ Sex } \\
\hline Male & $166(73.45)$ & 10 & 156 & \multirow[t]{2}{*}{0.156} \\
\hline Female & $60(26.55)$ & 7 & 53 & \\
\hline \multicolumn{5}{|l|}{ Smoking status } \\
\hline Yes & $112(51.38)$ & 6 & 106 & \multirow[t]{2}{*}{0.167} \\
\hline No & $106(48.62)$ & 11 & 95 & \\
\hline \multicolumn{5}{|l|}{ Drinking status $\mathrm{s}^{\mathrm{a}}$} \\
\hline Yes & $66(30.28)$ & 1 & 65 & \multirow[t]{2}{*}{$0.026^{\mathrm{b}}$} \\
\hline No & $152(69.72)$ & 16 & 136 & \\
\hline \multicolumn{5}{|l|}{ TNM stage ${ }^{a}$} \\
\hline I & $21(9.81)$ & 2 & 19 & \multirow[t]{4}{*}{0.947} \\
\hline II & $42(19.63)$ & 3 & 39 & \\
\hline III & $130(60.75)$ & 10 & 120 & \\
\hline IV & $21(9.81)$ & 1 & 20 & \\
\hline \multicolumn{5}{|l|}{ Depth of tumor invasion ${ }^{a}$} \\
\hline pT1 & $11(5.19)$ & 1 & 10 & \multirow[t]{4}{*}{0.761} \\
\hline pT2 & $24(11.32)$ & 3 & 21 & \\
\hline pT3 & $79(37.26)$ & 6 & 73 & \\
\hline pT4 & $98(46.23)$ & 6 & 92 & \\
\hline \multicolumn{5}{|l|}{ Lymph node involvement ${ }^{\mathrm{a}}$} \\
\hline pNO & $45(21.33)$ & 8 & 37 & \multirow[t]{2}{*}{$0.0036^{\mathrm{b}}$} \\
\hline pN1-pN3a & $166(78.67)$ & 8 & 158 & \\
\hline \multicolumn{5}{|l|}{ Presence of metastasis ${ }^{\mathrm{a}}$} \\
\hline M0 & $193(90.19)$ & 15 & 178 & \multirow[t]{2}{*}{$>0.999$} \\
\hline M1 & $21(9.81)$ & 1 & 20 & \\
\hline \multicolumn{5}{|l|}{ HP infection ${ }^{\mathrm{a}}$} \\
\hline Negative & $29(56.86)$ & 3 & 26 & \multirow[t]{2}{*}{$>0.999$} \\
\hline Positive & $22(43.14)$ & 2 & 20 & \\
\hline \multicolumn{5}{|l|}{ Pathological type $\mathrm{a}^{\mathrm{a}}$} \\
\hline Adenocarcinoma & $128(62.14)$ & 9 & 119 & \multirow[t]{2}{*}{0.581} \\
\hline Mucinous carcinoma & $78(37.86)$ & 7 & 71 & \\
\hline \multicolumn{5}{|l|}{ Histological grade ${ }^{\mathrm{a}}$} \\
\hline Well-differentiated & $11(6.59)$ & 1 & 10 & \multirow[t]{2}{*}{0.571} \\
\hline Moderately/poorly & $156(93.41)$ & 11 & 145 & \\
\hline
\end{tabular}

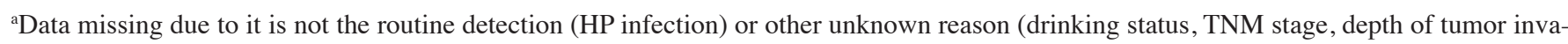
sion, lymph node involvement, presence of metastasis, pathological type and histological grade). ${ }^{\mathrm{b}} \mathrm{P}<0.05$. MSS, microsatellite stable; $\mathrm{H}$, high; L, low; MSI, microsatellite instability.

new peak compared with that in the product from the adjacent normal tissue using GeneMarker v1.75 (SoftGenetics, LLC). For the heterozygous locus, a sample was determined to exhibit $\mathrm{LOH}$ when one of the alleles was completely or partially lost. More specifically, the ratio of the peak height between the two alleles in the adjacent normal tissue compared with that in the tumor tissue was $<0.67$ or $>1.5$. The peak height was determined using GeneMarker v1.75 (SoftGenetics, LLC).
The mutation profiles of 91 MS loci in tumor-related genes and 5 B5 loci in the training group $(n=90)$ were first examined and then validated using a sub-set of the 91 loci $(n=27)$ and 5 B5 loci in the second set of samples $(n=136)$. The present study evaluated the efficiency of the loci using the Efficiency Score (ES). The ES

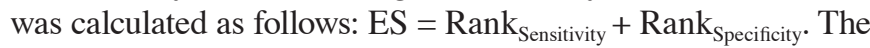
lower the ES was, the more efficient the locus was. Sensitivity equals the number of detected MSI/the total. Specificity equals the number of detected MSS/the total number. 
DNA sequencing. To validate the STR scanning results, PCR fragments were cloned into the PMD19-TVector (TA cloning Vector) (Takara Bio, Inc.), and sequence analysis was performed using an ABI 3730XL DNA Sequencer and Sanger sequencing, and was commissioned to be completed by Annoroad Gene Technology Co., Ltd. To define the occurrence of MSI, the sequencing results of the examined loci in MSI-positive GC tissues were compared with those in the adjacent normal tissues.

Statistical analysis. Descriptive statistics were used to summarize the relevant clinicopathological information. The comparation of MSI/LOH frequency, core sequence length and repeat unit of mono-, di-, tri-, tetra- and penta- was analyzed using one-way ANOVA and a Tukey's post hoc test. The comparation of age in different groups was analyzed using an unpaired t-test and the data is presented as mean \pm SD.; sex, smoking, drinking, lymph node involvement, TNM stage, depth of tumor invasion, metastasis, HP infection, pathological type, and histological grade, were analyzed using a Pearson's $\chi^{2}$ test or a Fisher's exact test, and Spearman's correlation analysis was used to investigate the correlation between intrinsic features (length and repeat number of the MS core sequence) and the MSI/LOH frequency. Overall survival [OS; the time between the start of randomization (which means the patients received different treatments after surgical resection) and death] and disease-free survival (DFS; the time between the start of randomization and recurrence of the disease) analyses were determined using the Kaplan-Meier method, and statistically analyzed using a log-rank test. Data analysis was performed using SPSS Statistics v16.0 software (SPSS, Inc.). $\mathrm{P}<0.05$ was considered to indicate a statistically significant difference.

\section{Results}

MSI/LOH analysis in tumor-related genes. A total of 586 variations, including MSI and LOH events, were identified when analyzing $91 \mathrm{MS}$ markers in 20 tumor-related genes, using STR scanning in the first set of patients with $\mathrm{GC}(\mathrm{n}=90)$. It was revealed that 35 out of the $90 \mathrm{GC}$ samples (38.9\%) did not exhibit any MSI or LOH. Among the 91 loci, $91.2 \%$ were mutated in $\geq 1$ patient (Fig. S1; Table SII). To validate the scanning results, one of the MSI-positive GC sample of locus E2F4 and its adjacent normal tissue were selected for TA clone sequencing. The STR scanning result in adjacent normal tissue was $281 / 281$ bp and was mutated to $281 / 284 \mathrm{bp}(+3 \mathrm{bp})$ in the matched tumor sample. In addition, there was a TGC (3 bp) insertion in the sequencing result of the tumor tissue (Fig. 1). The MSI/LOH frequency of the individual MSs not only varied markedly from locus to locus, but also from gene to gene (Fig. 2A). There was no significant difference in MS variation among MMR genes, oncogenes or TS genes ( $\mathrm{P}=0.332$; Fig. 2B). However, most MS variations in the MMR genes $(16 / 23 ; 69.6 \%)$ exhibited consistency compared with that in oncogenes, and similarly, $87.0 \%(20 / 23)$ of the mutations in the MMR genes were consistent compared with that in the TS genes. In addition, the consistency between MS variations in oncogenes (19/32, $59.4 \%)$ and TS genes $(19 / 39,48.7 \%)$ were much lower
(Fig. 2C). The MS variation frequency varied markedly between the different loci; however, the differences between the MSI/LOH profiles and the MMR genes, oncogenes and TS genes suggested that the mutations (MSI/LOH) occurring in the genes were not completely random, but followed a certain regularity. Among the mutations that occurred in MMR genes, only $8.70 \%(2 / 23)$ of $\mathrm{MSI} / \mathrm{LOH}$ events occurred in only the MMR genes, while $91.30 \%(21 / 23)$ of MSI/LOH events simultaneously occurred in the MMR genes and oncogenes or TS genes (Fig. 2C).

Effect of the intrinsic features of MS on mutations. In cancer, the causes of MSI/LOH are not completely understood (33). To investigate the intrinsic features, which may contribute to $\mathrm{MSI} / \mathrm{LOH}$ frequency in tumors, the present study analyzed the repeat units, length and repeated motif of the 91 MS loci. The MS locus number of the mono-, di-, tri-, tetra-, penta-MS and compounds was 42, 22, 11, 9, 2 and 5, respectively (Fig. 3A).

It was first revealed that the length and repeat number of the MS core sequence were positively correlated with MSI and $\mathrm{LOH}$ incidence $\left(\mathrm{r}_{\mathrm{s}}=0.53 ; \mathrm{P}<0.001\right.$ and $\mathrm{r}_{\mathrm{s}}=0.365 ; \mathrm{P}<0.01$; Fig. 3B and C, respectively).

The MSI/LOH frequency of the di-MS group was markedly higher compared with that in the tri- MS groups $(\mathrm{P}<0.01)$; however, it was unclear if this was due to the different repeat motifs or the different length/repeat number of the core sequence. The core sequence length of di-MS was significantly longer compared with mono-MS $(\mathrm{P}<0.001)$ and the repeat number of mono-MS was the highest among all the type of MS followed by di-MS (5 compound MSs were excluded, so the loci number was 91-5=86) (Fig. 3D). Due to the limited number of tri-, tetra- and penta-MS loci, only the mono- and di-MS loci were selected for the next step. To investigate whether the diversity in length and repeat number of the core sequence contributed to the different MSI/LOH frequency, the MSI/LOH frequency was further compared between the di- and mono-MS groups, when the same length or repeat number was noted. Based on the trend of the curves, it seemed that for the same length, the MSI/LOH frequency was not very different, since crossover was observed between the two curves (Fig. 3E). However, for the same repeat number, the MSI/LOH frequency of the di-MS loci was higher compared with that in the mono-MS loci (Fig. 3F). Therefore, it was hypothesized that the difference in the MSI/LOH rate between mono- and di-MS was mainly due to the different lengths rather than the repeat motif or repeat number only.

MSI/LOH of the validation loci in 226 GC samples. Based on the frequency and sample coverage of the MSI/LOH within the tumor-associated genes, in the first set of samples $(n=90)$, a total of 27 loci in 15 genes were optimized. Subsequently, the same method was used to detect the variation of the 27 selected loci and 5 B5 panel loci in the second set of 136 samples $(226-90=136)$. The results are shown in Fig. S2.

The results of the MSI/LOH in the 32 loci in the first set $(n=90)$ and second set $(n=136)$ of patients with GC were integrated in the validation group $(n=90+136=226)$ (Fig. 4). The MSI frequencies of the 32 loci in the 226 samples are shown 


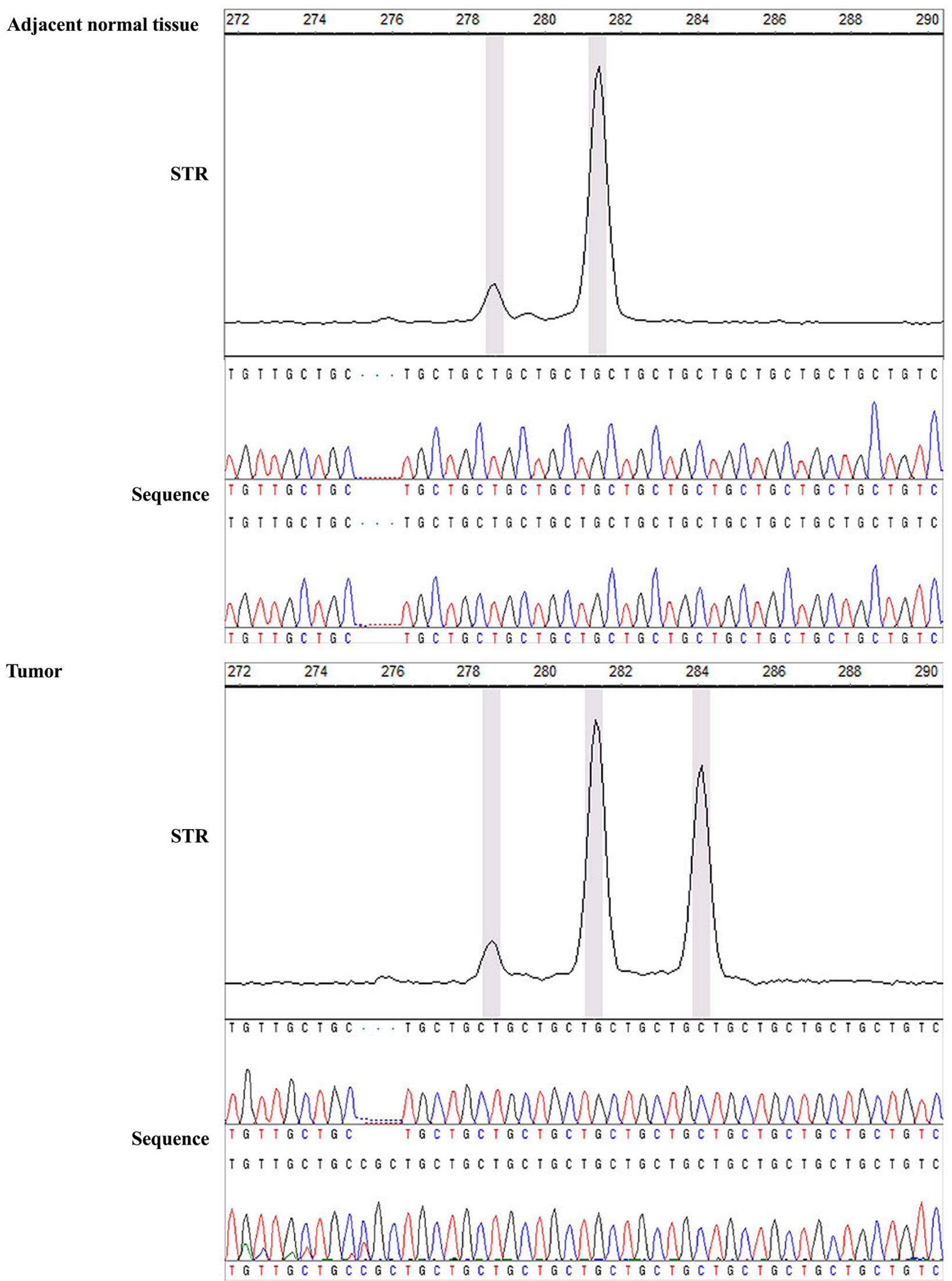

Figure 1. Short tandem repeats scanning and TA clone sequencing results. The microsatellite locus of E2F transcription factor 4 was used as an example.

in Fig. 4A. The MSI frequencies of the most frequent MS loci were: D2S123 (19/226, 8.41\%), D17S250 (19/226, 8.41\%), BAT25 (18/226, 7.96\%), P21-1 (17/226, 7.52\%), MCC26 (17/226,
7.52\%), TGFBR2-35 (17/226, 7.52\%), BAT26 (17/226, 7.52\%), ERBB2-12 (16/226, 7.08\%), CTNNB1-(9+10) (16/226, 7.08\%), CTNNB1-4 (16/226, 7.08\%) and ERBB2-25 (16/226, 7.08\%). 

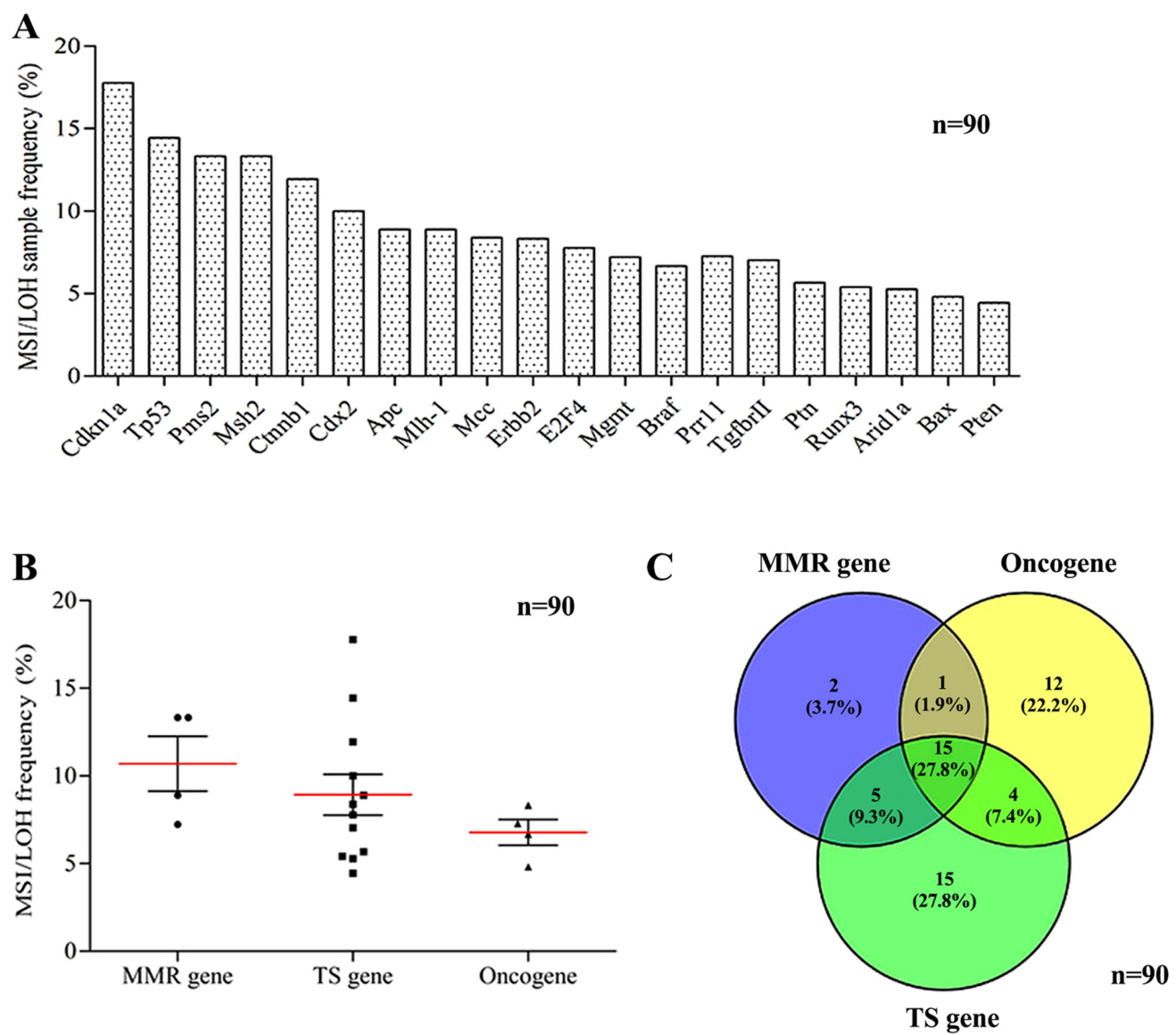

Figure 2. MSI/LOH frequency of the tumor-related genes in patients with GC. (A) MSI/LOH frequency in the 20 cancer-related genes. (B) Mean MSI/LOH frequency among the MMR genes, oncogenes and TS genes. The dots represent the frequency of MSI/LOH in each gene. P-values were determined using one-way ANOVA. (C) Comparison of the MSI/LOH profiles among the MMR genes, oncogenes and TS genes. MSI, microsatellite instability; LOH, loss of heterozygosity; MMR, mismatch repair; TS, tumor suppressor.

Furthermore, the highest LOH occurrence rate was observed for TP53-1 (37/226, 16.37\%), followed by ERBB2-12 (30/226, $13.37 \%)$, CTNNB1-(9+10) $(23 / 226,10.18 \%)$, D2S123 (22/226, $9.73 \%)$, MSH2-7 (22/226, 9.73\%) and RUNX3-2 (21/226, 9.29\%) (Fig. 4B).

MS panel for MSI-high (MSI-H) detection. In previous study, MSI-H was defined as MSI occurrence at $\geq 40 \%$ of the loci of the B5 panel, while occurrence at $<40 \%$ of the loci has been defined as MSI-low (MSI-L) and no MSI occurrence at all detected loci was defined as microsatellite stable (MSS) (14). In the present study, the B5 panel analysis revealed that among the 226 samples, 17 (7.5\%) were MSI-H, 9 (4.0\%) were MSI-L and 200 (88.5\%) were MSS. The detected loci exhibited different sensitivity and specificity (Table II). The optimal locus to define MSI-H samples was BAT26, which had a sensitivity and specificity of $100 \%$. This was followed by BAT25 with a sensitivity of $100 \%$ and a specificity of $99.5 \%$. Therefore, BAT26 and BAT25 were the most sensitive loci to identify MSI-H status in GC. The top 5 most efficient loci were BAT26, BAT25, CTNNB1-(9+10), ERBB2-25 and TGFBR2-35. However, the B5 panel loci, D2S123, D5S346 and D17S250 had a higher ES, which was associated with a relatively low efficiency for the definition of MSI-H status. The aim of this part was to compare the detection efficiency of the loci in tumor-related genes and B5 loci and find the top 5 loci, so we just listed the loci which score whose score was $>10$ (Table II).

MSI/LOH status and clinical features. Numerous studies have demonstrated that the MSI-H status was associated with the clinicopathological features of patients with GC; however, the results remain ambiguous $(34,35)$. The present study investigated the association between MSI-H status detected using the B5 panel and clinicopathological characteristics. The results indicated that MSI-H status was associated with drinking $(\mathrm{P}=0.026)$ and the absence of lymph node involvement $(\mathrm{P}=0.0036)$ In addition, MSI-H status was slightly more common in elderly individuals $(\mathrm{P}=0.074$; Table I). However, there was no association between MSI-H status and the other clinicopathological characteristics (Table I).

The association between the MSI/LOH profile at each locus ( $\mathrm{n}=27)$ in the tumor-related genes/the B5 panel $(n=5)$ and 5 important clinical features (lymph node involvement, tumor invasion depth, TNM Stage, pathological type and the presence of metastasis) was further analyzed in 226 GC samples (Table III).

The results demonstrated that the MSI status of 12 loci, including BAT25 $(\mathrm{P}=0.008)$, BAT26 $(\mathrm{P}=0.008), \mathrm{D} 2 \mathrm{~S} 123$ $(\mathrm{P}=0.049), \mathrm{D} 17 \mathrm{~S} 250 \quad(\mathrm{P}=0.012), \mathrm{MLH} 1-2 \quad(\mathrm{P}=0.008)$, MGMT-5 $(\mathrm{P}=0.012), \mathrm{CTNNB1}-(9+10) \quad(\mathrm{P}=0.005)$, ERBB2-12 $(\mathrm{P}=0.021), \mathrm{ERBB} 2-18(\mathrm{P}=0.007), \mathrm{ERBB} 2-25$ 
A

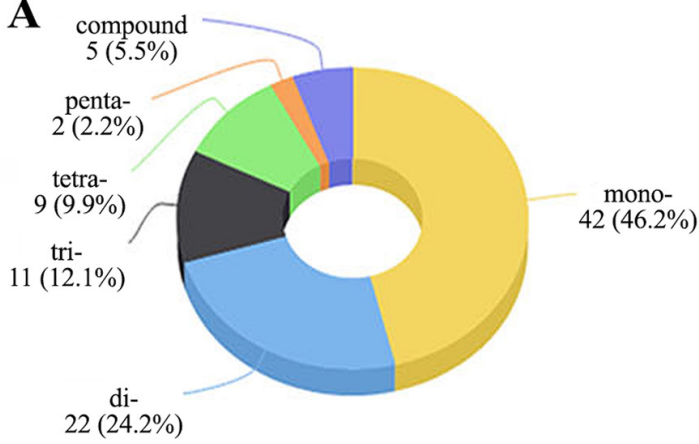

C

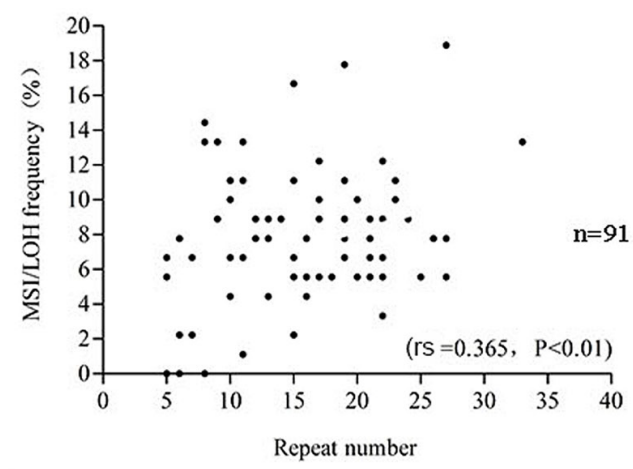

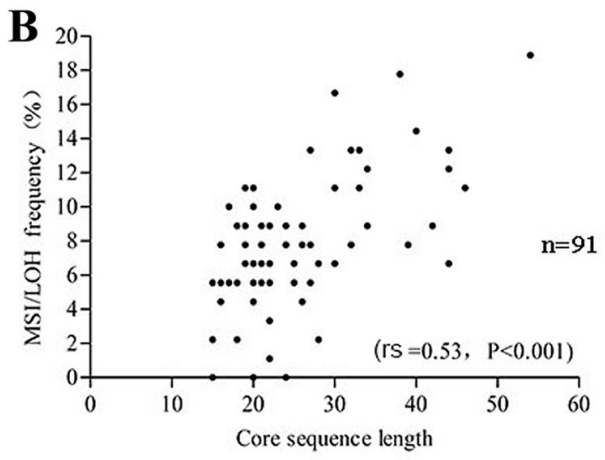

D
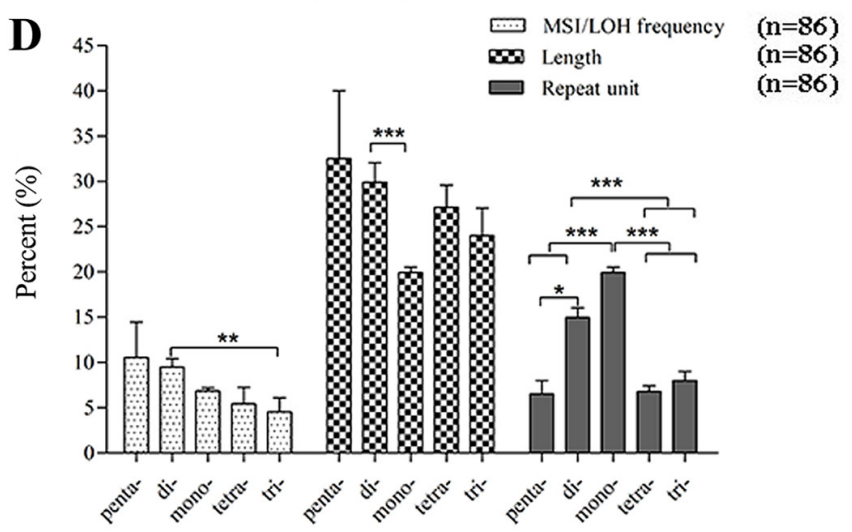

$\mathbf{E}$

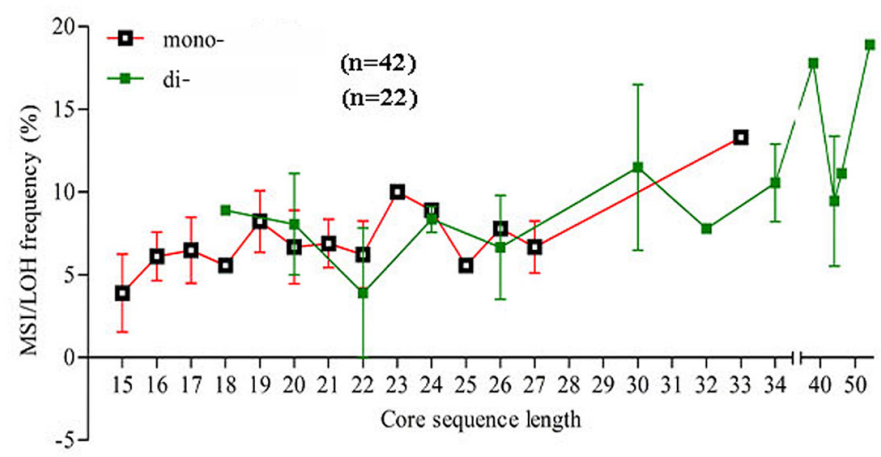

F

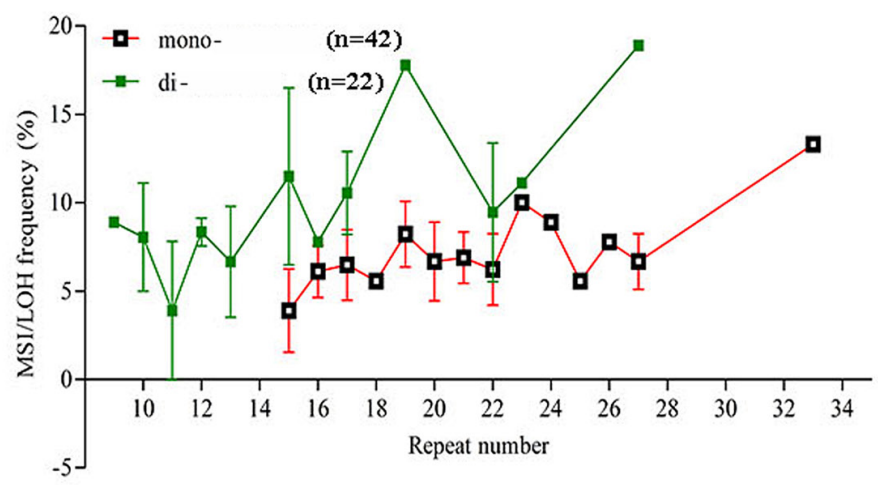

Figure 3. Effect of the intrinsic features of MS on MSI/LOH occurrence. (A) Repeat motif composition of the 91 MS loci. Correlation between (B) core sequence length and (C) repeat number with MSI/LOH frequency. P-values were determined using a Spearman's correlation. (D) Mean MSI/LOH frequency, length and repeat number of different motif groups. P-values were determined using one-way ANOVA followed by Tukey's post hoc test. (E) MSI frequency of different sequence lengths in the mono- and di-MS groups. (F) MSI/LOH frequency of different repeat numbers in the mono- and di-MS groups. * $<0.05$, ${ }^{* *} \mathrm{P}<0.01$ and ${ }^{* * *} \mathrm{P}<0.001$. MS, microsatellite; MSI, microsatellite instability; LOH, loss of heterozygosity; mono-, mononucleotide; di-, dinucleotide; tetra-, tetranucleotide; tri-, trinucleotide; penta-, pentanucleotide.

the LOH in MGMT-10 $(\mathrm{P}=0.01)$ were also significantly associated with $\mathrm{T} 1 / \mathrm{T} 2$ stage of depth of tumor invasion. In addition, the LOH status of MGMT-10 (P=0.0003) and 
Table II. Efficiency of MSI-H detection of the MS loci.

\begin{tabular}{|c|c|c|c|c|c|c|c|}
\hline \multirow[b]{2}{*}{ Loci } & \multicolumn{3}{|c|}{ Sensitivity } & \multicolumn{3}{|c|}{ Specificity } & \multirow[b]{2}{*}{ ES } \\
\hline & Number of MSI & Rate (\%) & Rank & Number of MSS & Rate (\%) & Rank & \\
\hline ВАT26 & 17 & 100 & 1 & 209 & 100 & 1 & 2 \\
\hline BAT25 & 17 & 100 & 1 & 208 & 99.5 & 2 & 3 \\
\hline CTNNB1-(9+10) & 16 & 94.1 & 2 & 209 & 100 & 1 & 3 \\
\hline ERBB2-25 & 16 & 94.1 & 2 & 209 & 100 & 1 & 3 \\
\hline TGFBR2-35 & 16 & 94.1 & 2 & 208 & 99.5 & 2 & 4 \\
\hline ERBB2-12 & 15 & 88.2 & 3 & 208 & 99.5 & 2 & 5 \\
\hline D2S123 & 16 & 94.1 & 2 & 206 & 98.6 & 4 & 6 \\
\hline P21-1 & 15 & 88.2 & 3 & 207 & 99 & 3 & 6 \\
\hline D5S346 & 13 & 76.5 & 5 & 208 & 99.5 & 2 & 7 \\
\hline D17S250 & 15 & 88.2 & 3 & 205 & 98.1 & 5 & 8 \\
\hline MLH1-2 & 14 & 82.4 & 4 & 209 & 100 & 1 & 8 \\
\hline PRR11-17 & 14 & 82.4 & 4 & 208 & 99.5 & 2 & 8 \\
\hline TGFBR2-11 & 12 & 70.6 & 6 & 208 & 99.5 & 2 & 8 \\
\hline PTN-41 & 12 & 70.6 & 6 & 208 & 99.5 & 2 & 8 \\
\hline CTNNB1-4 & 13 & 76.5 & 5 & 206 & 98.6 & 4 & 9 \\
\hline MCC-26 & 13 & 76.5 & 5 & 205 & 98.1 & 5 & 10 \\
\hline
\end{tabular}

Microsatellite; MSI, microsatellite instability; ES, efficiency score.
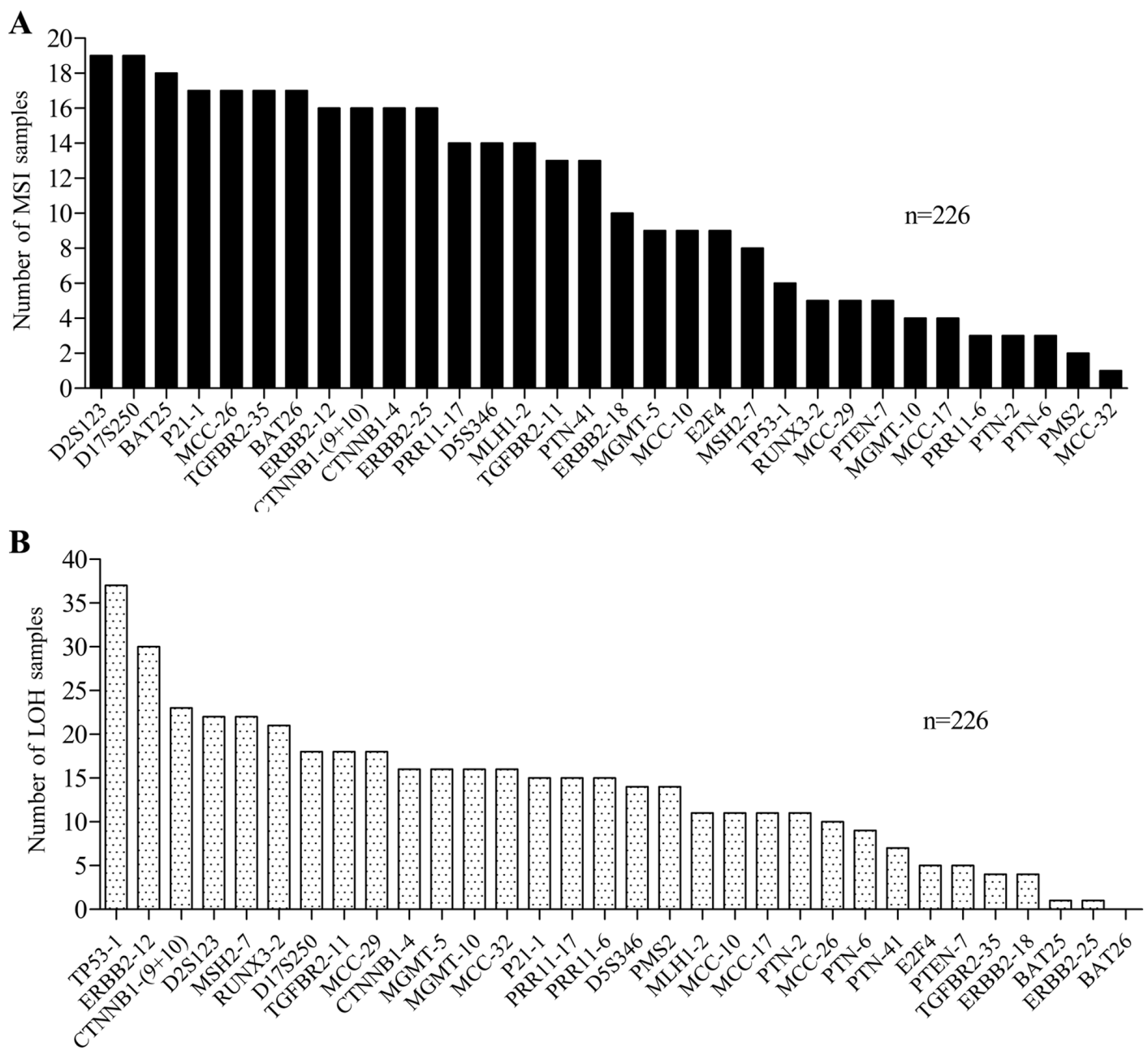

Figure 4. MSI/LOH profile of the selected loci in GCs. (A) MSI profile and (B) LOH profiles of the 32 loci in the 226 samples. 
Table III. Association between the MSI/LOH profile in the tumor-related genes and clinicopathological characteristics.

\begin{tabular}{|c|c|c|c|c|}
\hline \multirow[b]{2}{*}{ Clinicopathological characteristic } & \multicolumn{2}{|c|}{ MSI loci } & \multicolumn{2}{|c|}{ LOH loci } \\
\hline & Name & P-value & Name & P-value \\
\hline \multicolumn{5}{|l|}{ Lymph node involvement } \\
\hline \multirow[t]{12}{*}{ pNO } & BAT25 & 0.008 & - & - \\
\hline & BAT26 & 0.008 & & \\
\hline & $\mathrm{D} 2 \mathrm{~S} 123$ & 0.049 & & \\
\hline & $\mathrm{D} 17 \mathrm{~S} 250$ & 0.012 & & \\
\hline & MLH1-2 & 0.008 & & \\
\hline & MGMT-5 & 0.012 & & \\
\hline & CTNNB1-(9+10) & 0.005 & & \\
\hline & ERBB2-12 & 0.021 & & \\
\hline & ERBB2-18 & 0.007 & & \\
\hline & ERBB2-25 & 0.005 & & \\
\hline & TGF $\beta-11$ & 0.008 & & \\
\hline & TGF $\beta-35$ & 0.002 & & \\
\hline pN1-pN3a & - & - & - & - \\
\hline \multicolumn{5}{|l|}{ Tumor invasion depth } \\
\hline pT1T2 & TP53-1 & 0.003 & MGMT-10 & 0.01 \\
\hline pT3T4 & - & - & - & - \\
\hline \multicolumn{5}{|l|}{ TNM stage } \\
\hline \multirow[t]{2}{*}{ I/II } & - & - & MGMT-10 & 0.0003 \\
\hline & & & PTN-2 & 0.017 \\
\hline III/IV & - & - & MCC-17 & 0.036 \\
\hline \multicolumn{5}{|l|}{ Pathological type } \\
\hline \multirow[t]{2}{*}{ Adenocarcinoma } & - & - & TP53-1 & 0.001 \\
\hline & & & ERBB2-12 & 0.025 \\
\hline Mucinous carcinoma & - & - & - & - \\
\hline
\end{tabular}

MSI, microsatellite instability; LOH, loss of heterozygosity.

PTN-2 $(\mathrm{P}=0.017)$ was associated with TNM stage $\mathrm{I} / \mathrm{II}$, while LOH in MCC-17 ( $\mathrm{P}=0.036)$ was significantly associated with TNM stage III/IV. Finally, the LOH status of TP53-1 $(\mathrm{P}=0.001)$ and ERBB2-12 $(\mathrm{P}=0.025)$ was significantly associated with adenocarcinoma compared with that in mucinous carcinoma (Table III). However, the MSI/LOH of the loci in tumor-related genes were not significantly associated with the presence of metastasis.

MSI/LOH status and prognosis. At present, studies analyzing the prognostic value of MSI remain controversial (17). The present study investigated the association between MSI status of the B5 panel and prognosis (OS, $n=176$; DFS, $n=177$; the low number of samples for OS and DFS is because the follow-up information of some patients were lacking). The results revealed that there was no association between MSI-H status and OS ( $\mathrm{P}=0.9521)$ or DFS ( $\mathrm{P}=0.8904$; Fig. 5A and $\mathrm{B})$.

The present study further analyzed the association between $\mathrm{MSI} / \mathrm{LOH}$ status in the tumor-related genes and survival. The results demonstrated that the MSI or LOH in 6 loci in the tumor-related genes were significantly associated with prognosis (Fig. 5). The MSI in PRR11-6 (P=0.019) and MGMT-10
$(\mathrm{P}=0.018)$ was associated with poor OS (Fig. 5C and D). Furthermore, the MSI in PRR11-6 ( $\mathrm{P}=0.0045)$, RUNX3-2 $(\mathrm{P}=0.0008), \mathrm{MCC}-17(\mathrm{P}=0.04)$ and MGMT-5 $(\mathrm{P}=0.0507)$ were significantly associated with poor DFS (Fig. 5E-H). In addition, the LOH in P21-1 ( $\mathrm{P}=0.0437)$ was significantly associated with worse DFS (Fig. 5I). Notably, all six loci predicted a poor prognosis, and none of these loci were mononucleotide loci.

\section{Discussion}

Increasing evidence suggests that MSI is one of the most robust subgroups of GC with specific molecular features $(10,11)$. In recent years, MSI has also been developed as a predictive biomarker for the response to immune checkpoint inhibitors (programmed cell death protein 1/programmed death-ligand 1 blockade) in GC. For example, it was proved that PD-L1 positive tumors had the best outcome observed for patients with MSI-high/PD-L1 positive tumors and those with MSS/PD-L1 negative tumors had the worst outcome (36). However, one of the most important problems, which seriously hinders the practical application of MSI in GC, is that a wide variety of different MS markers have been used to investigate MSI 
A

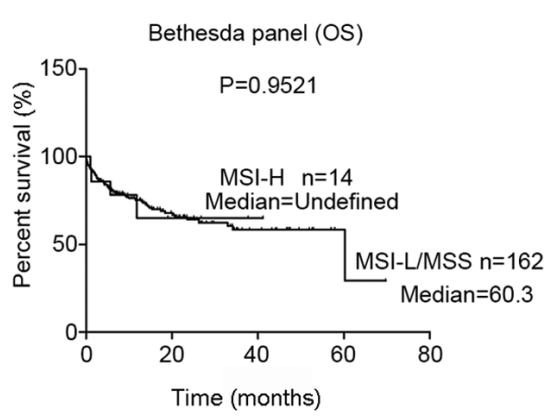

D

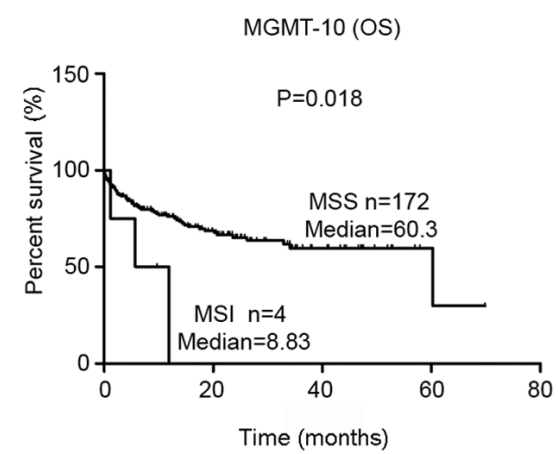

G

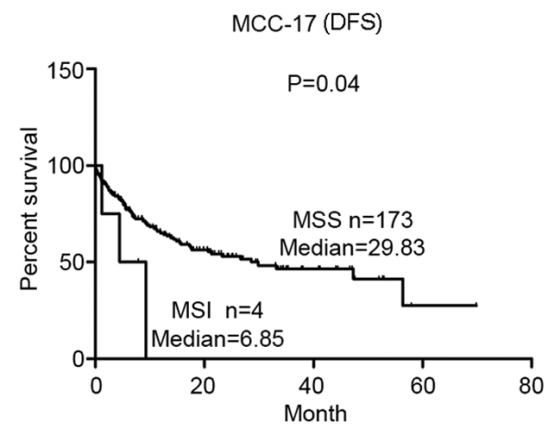

B

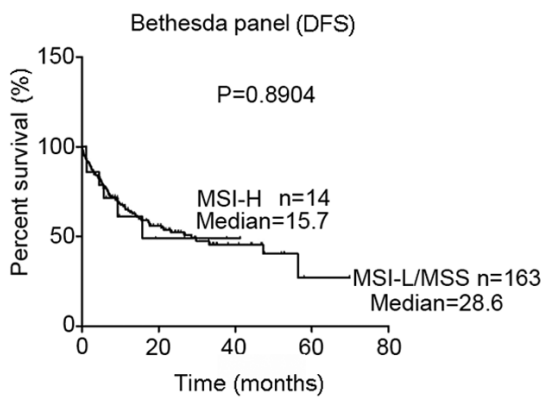

$E$

PRR11-6 (DFS)

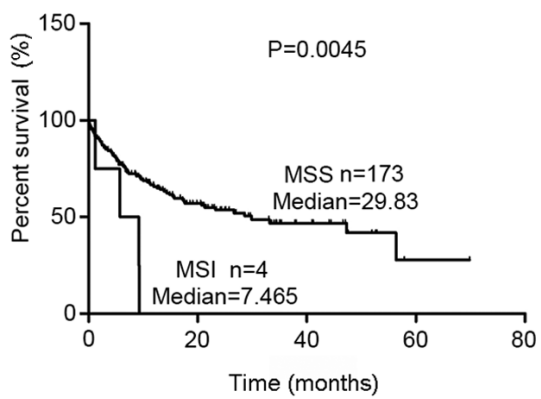

$\mathrm{H}$

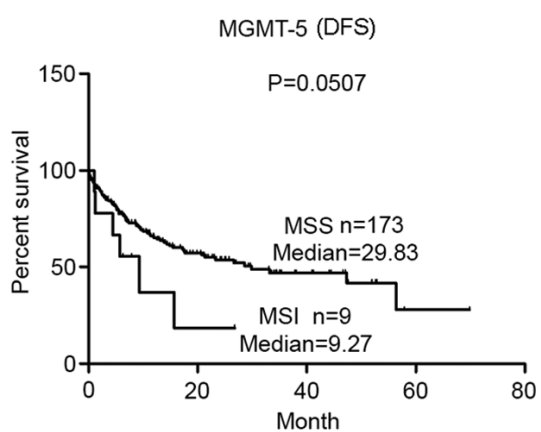

C

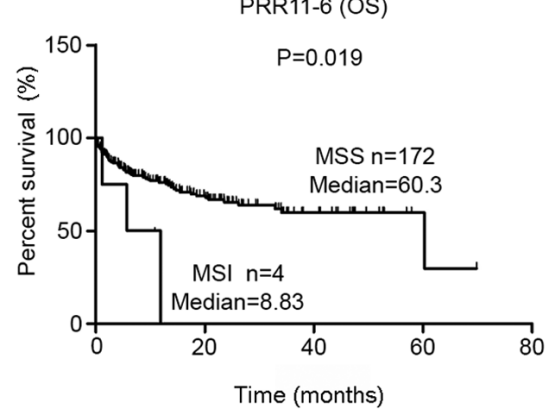

F

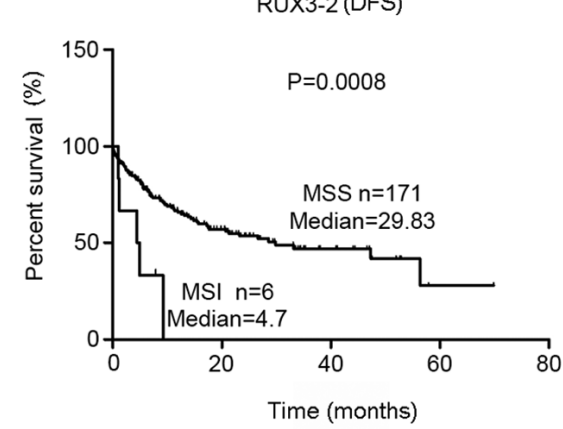

I

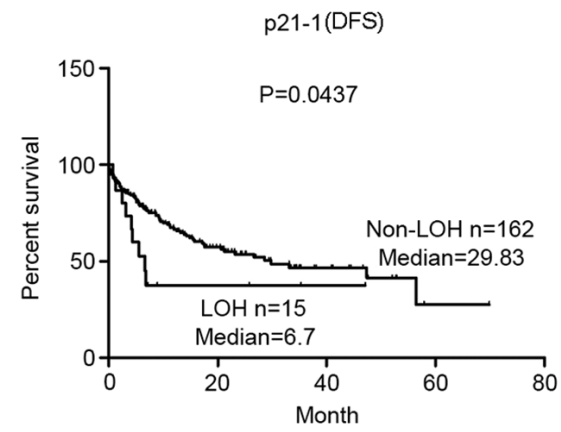

Figure 5. Association between MSI/LOH and the prognosis of gastric cancer. Association between MSI-high status of the Bethesda panel and (A) OS or (B) DFS. Association between MSI in (C) PRR11-6 and (D) MGMT-10 with OS, and MSI in (E) PRR11-6, (F) RUX3-2, (G) MCC-17 and (H) MGMT-5 with DFS. (I) Association between LOH of p21-1 and DFS. P-values were determined using Kaplan-Meier analysis and the log-rank test. MSI, microsatellite instability; LOH, loss of heterozygosity; OS, overall survival; DFS, disease-free survival; MSS, microsatellite stable; H, high; L, low.

status (37). This includes the MS panel used in the study by Angell et al (36), containing five mononucleotide repeat markers (NR27, NR21, NR24, BAT25 and BAT26). This was different from numerous other studies, which used a different panel of loci, for example: A combination of mono- and dinucleotide markers (i.e., BAT25, BAT26, D1S104, D2S123, D3S1611, D5S107, D17S261 and D18S342) (38), only dinucleotide markers (i.e., D2S123, D3S966, D3S1076, D5S82, DP1, D10S197, D11S904, D13S175 and NM23) (39), only one mononucleotide marker (i.e., BAT26) (40) and the present study (B5 panel and markers in tumor-related genes). Therefore, it is important to identify more efficacious and specific loci for GC MSI detection.

The present study examined the MSI of 91 loci, all of which were located in GC-related genes in 90 GC samples. To further characterize the genetic alterations found in the GC samples, the present study also evaluated $\mathrm{LOH}$, using the same panel of loci. As expected, the majority of the loci (91.2\%) exhibited MSI/LOH mutations. The results revealed that, in a patient who possessed a mutation in the oncogenes or TS genes, this was usually accompanied by a mutation in the MMR genes; however, there was no significant association between the mutation profile of oncogenes and TS genes. This suggested that instability in the MMR genes served an important role in the mutation status of the oncogenes and TS genes. This is in accordance with previous studies, which indicated that the loss-of-function of the MMR genes was associated with a highly mutated phenotype in key oncogenes and TS genes $(41,42)$. Human MS evolution research has illustrated that the fragility is primarily determined by the base composition $(33,43)$. According to the present data, the MS mutation rate was more likely determined by the length of the core sequence, but not by the type of repeat motif or the repeat number only. 
To identify the effective loci which have a potential role in the prediction of clinical features or the prognosis of $\mathrm{GC}$, the present study further analyzed 27 potential loci among the 91 loci in the tumor-related genes. In addition to the B5 panel, 27 loci were detected in the second set of GC samples. Subsequently, the mutations at these sites, in the two sets of patients were integrated. The results demonstrated that the B5 loci, D2S123 (8.41\%), D17S250 (8.41\%) and BAT25 presented a relatively higher potential of variation, whereas the locus D5S346 did not exhibit a high rate of MSI or LOH in GC. The results indicated that, although recommended as classic markers in CRC, not all of the five loci in the B5 panel were sensitive to MSI in GC. In addition, TP53-1 was considered to be the most LOH-prone locus, which was in line with a previous study, which suggested that TP53 was the most mutated gene (18).

Currently, the loci used in GC research, particularly the B5 panel recommended by the National Cancer Institute, are mainly based on hereditary non-polyposis CRC research (44). In the present study, as defined by the B5 panel, MSI-H GC accounted for $7.5 \%$, which was consistent with previous studies, revealing that the MSI-H incidence of GC ranges between 5.6 and $33.3 \%(45,46)$. A combination of the sensitivity and specificity for the detection of MSI was used to evaluate the efficiency of the loci. Notably, the top 5 effective loci (BAT26, BAT25, CTNNB1-(9+10), ERBB2-25 and TGFBR2-35) were mononucleotide MSs, which was similar to the results of a study, which indicated that mononucleotide markers are more effective for the identification of MSI status compared with that in dinucleotide markers (47). The predictive and prognostic role of MSI status has been well established in CRC; however, there is still a large heterogeneity in the results regarding the association between MSI and clinicopathological features across different GC studies $(34,35)$. To the best of our knowledge, few studies have explored the association between drinking and MSI $(48,49)$. The present study demonstrated that the MSI-H status of the B5 panel was significantly associated with drinking $(\mathrm{P}=0.026)$. In addition, the results revealed that the MSI-H status of the B5 panel was also significantly associated with the absence of lymph node involvement $(\mathrm{P}=0.0036)$ and slightly more common in elderly people $(\mathrm{P}=0.074)$. This was similar to the results reported in a previous meta-analysis (50).

The present study subsequently evaluated the association between the MSI/LOH in the loci of tumor-related genes and clinicopathological characteristics, which are likely to affect GC treatment, including lymph node involvement, the depth of tumor invasion, presence of metastasis, TNM stage and pathological type.

It remains a challenge to predict the presence of lymph node metastasis in clinical settings, even following surgery, due to the preference of limited resections (51). Due to its significance in the prognosis of GC, a previous study investigated lymph node metastasis according to MSI status and the result indicated that MSI-H phenotype was significantly associated with the presence of lymphatic invasion $(\mathrm{P}=0.036)(52)$. In the present study, the MSI status of 12 single loci, including 4 from the B5 panel and 8 from the tumor-related genes, was significantly associated with lymph node metastasis as previously reported. In addition, it was revealed that patients with a MSI in TP53-1 or a LOH in MGMT-10 were more prone to having earlier stages of depth of tumor invasion. Patients presenting with LOH in MGMT-10 or PTN-2 were more likely to be in earlier TNM stages, while patients with $\mathrm{LOH}$ in MCC-17 were likely to present with advanced TNM stage. The LOH in TP53-1 or ERBB2-12 was higher in adenocarcinoma compared with that in mucinous carcinoma. These findings indicated that the MSI/LOH at these loci may serve an important role in lymph node metastasis, tumor invasion, TNM or pathological type, and may be useful and applicable for the prediction of clinical features in patients with GC.

The association between the survival of patients with GC and MSI has yet to be determined. As evaluated by the B5 panel, patients with GC and MSI-H or MSI-L/MSS status exhibited similar outcomes with respect to OS and DFS. The results from the present study are inconsistent with a previous study, which demonstrated that the prognosis of patients in the MSI group was improved compared with that in patients with MSS GC (50). This could be due to the different loci used for the determination of MSI. However, the present study found that mutations of 6single loci in tumor-related genes, including MSI in five loci and $\mathrm{LOH}$ in 1 loci, were associated with poorer outcomes with respect to OS or DFS. Among these valuable loci (Fig. 5), only the MSI status of MGMT-5 was significantly associated with lymph node involvement (Table III), which indicates that lymph node involvement maybe an important factor in the association between the MSI status of MGMT-5 and survival. In the present study it was found that, with the exception of the MSI status in MGMT-5, all the other MSI/LOH events, which were associated with prognosis, were not associated with the clinical features, indicating that the MSI/LOH status of these loci maybe a prognostic factor without the affect from other clinical features. However, the predictive impact of MSI or MMR status and survival remains a contentious issue (50). The possible reasons may be due to i) Numerous other important clinical features not being analyzed and ii) Not enough patients with GC were included in the present study.

There are also additional limitations to the present study. The 91 MS loci selected from the 20 genes were predetermined based on the PCR amplification efficacy, and not all MS loci in these tumor-related genes were included, potentially missing other important MSI loci in these genes. However, it was identified that the same repeat motif and similar repeat unit locus in the same gene exhibited highly consistent distribution and frequency of MSI events (data not shown). An important challenge for the future is to standardize the laboratory methodology for MSI detection in GC.

In conclusion, the present study provided several valuable MS biomarkers for the prediction of clinical features and prognosis, and has important implications for MSI detection in clinical applications and practice.

\section{Acknowledgements}

Not applicable.

\section{Funding}

The present study was supported by the National Science Foundation of China (grant no. 31772545) and Support Project 
of High-Level Teachers in Beijing Municipal Universities in the Period of 13th five-year Plan (grant no. IDHT 20170516).

\section{Availability of data and materials}

The datasets used and/or analyzed during the current study are available from the corresponding author on reasonable request.

\section{Authors' contributions}

$\mathrm{ZC}$ and $\mathrm{ZB}$ designed the study. XX performed the experiments. $\mathrm{XH}$ analyzed the data, wrote and revised the manuscript, and completed the submission. SZ, XD and CL participated in data analysis including offering advice and answers to some of the questions from the reviewers and editors. $\mathrm{ZC}, \mathrm{XD}$ and $\mathrm{XH}$ confirm the authenticity of all the raw data. All authors read and approved the final manuscript.

\section{Ethics approval and consent to participate}

The Ethics Committee of Beijing Friendship Hospital (Beijing, China) approved the study proposal (approval number, 2017-P2-013-03) and all patients involved in the study provided written informed consent.

\section{Patient consent for publication}

Not applicable.

\section{Competing interests}

The authors declare that they have no competing interests.

\section{References}

1. Bray F, Ferlay J, Soerjomataram I, Siegel RL, Torre LA and Jemal A: Global cancer statistics 2018: GLOBOCAN estimates of incidence and mortality worldwide for 36 cancers in 185 countries. CA Cancer J Clin 68: 394-424, 2018.

2. Ferro A, Peleteiro B, Malvezzi M, Bosetti C, Bertuccio P, Levi F, Negri E, La Vecchia C and Lunet N: Worldwide trends in gastric cancer mortality (1980-2011), with predictions to 2015, and incidence by subtype. Eur J Cancer 50: 1330-1344, 2014.

3. Smyth EC, Nilsson M, Grabsch HI, van Grieken NC and Lordick F: Gastric cancer. Lancet 396: 635-648, 2020.

4. Bang YJ, Van Cutsem E, Feyereislova A, Chung HC, Shen L, Sawaki A, Lordick F, Ohtsu A, Omuro Y, Satoh T, et al: Trastuzumab in combination with chemotherapy versus chemotherapy alone for treatment of HER2-positive advanced gastric or gastro-oesophageal junction cancer (ToGA): A phase 3 , open-label, randomised controlled trial. Lancet 376: 687-697, 2010.

4. Smyth EC and Moehler M: Pembrolizumab in first-line gastric cancer: Win, lose, or draw? JAMA Oncol 1: 1539-1541, 2020.

5. Bükakkaramikli NC, Blommestein HM, Riemsma R, Armstrong N, Clay FJ, Ross J, Worthy G, Severens J, Kleijnen J and Al MJ: Ramucirumab for treating advanced gastric cancer or gastro-oesophageal junction adenocarcinoma previously treated with chemotherapy: An evidence review group perspective of a NICE single technology appraisal. Pharmacoeconomics 35: 1211-1221, 2017.

6. Wilke H, Muro K, Van Cutsem E, Oh SC, Bodoky G, Shimada Y, Hironaka S, Sugimoto N, Lipatov O, Kim TY, et al: Ramucirumab plus paclitaxel versus placebo plus paclitaxel in patients with previously treated advanced gastric or gastro-oesophageal junction adenocarcinoma (RAINBOW): A double-blind, randomised phase 3 trial. Lancet Oncol 15: 1224$1235,2014$.
7. Cheong JH, Yang HK, Kim H, Kim WH, Kim YW, Kook MC, Park YK, Kim HH, Lee HS, Lee KH, et al: Predictive test for chemotherapy response in resectable gastric cancer: A multi-cohort, retrospective analysis. Lancet Oncol 19: 629-638, 2018.

8. Roh CK, Choi YY, Choi S, Seo WJ, Cho M, Jang E, Son T, Kim HI, Kim H, Hyung WJ, et al: Single patient classifier assay, microsatellite instability, and epstein-barr virus status predict clinical outcomes in stage II/III gastric cancer: Results from CLASSIC trial. Yonsei Med J 60: 132-139, 2019.

9. Choi YY, Jang E, Seo WJ, Son T, Kim HI, Kim HI, Hyung WJ, Huh YM, Noh SH and Cheong JH: Modification of the TNM staging system for stage II/III gastric cancer based on a prognostic single patient classifier algorithm. J Gastric Cancer 18: 142-151, 2018.

10. Cancer Genome Atlas Research Network: Comprehensive molecular characterization of gastric adenocarcinoma. Nature 513: 202-209, 2014.

11. Cristescu R, Lee J, Nebozhyn M, Kim KM, Ting JC, Wong SS, Liu J, Yue YG, Wang J, Yu K, et al: Molecular analysis of gastric cancer identifies subtypes associated with distinct clinical outcomes. Nat Med 21: 449-456, 2015.

12. Mizoshita T, Tsukamoto T, Cao X, Otsuka T, Ito S, Takahashi E, Nakamura S, Nakamura T, Yamamura Y and Tatematsu M: Microsatellite instability is linked to loss of hMLH1 expression in advanced gastric cancers: Lack of a relationship with the histological type and phenotype. Gastric Cancer 8: 164-172, 2005.

13. Ionov Y, Peinado MA, Malkhosyan S, Shibata D and Perucho M: Ubiquitous somatic mutations in simple repeated sequences reveal a new mechanism for colonic carcinogenesis. Nature 363: 558-561, 1993.

14. Boland CR, Thibodeau SN, Hamilton SR, Sidransky D, Eshleman JR, Burt RW, Meltzer SJ, Rodriguez-Bigas MA, Fodde R, Ranzani GN and Srivastava S: A national cancer institute workshop on microsatellite instability for cancer detection and familial predisposition: Development of international criteria for the determination of microsatellite instability in colorectal cancer. Cancer Res 58: 5248-5257, 1998.

15. Hause RJ, Pritchard CC, Shendure J and Salipante SJ: Classification and characterization of microsatellite instability across 18 cancer types. Nat Med 22: 1342-1350, 2016.

16. Fang WL, Chen MH, Huang KH, Chang SC, Lin CH, Chao Y, Lo SS, Li AF, Wu CW and Shyr YM: The clinicopathological features and genetic mutations in gastric cancer patients according to EMAST and MSI status. Cancers (Basel) 27: 551, 2020.

17. An JY, Kim H, Cheong JH, Hyung WJ, Kim H and Noh SH: Microsatellite instability in sporadic gastric cancer: Its prognostic role and guidance for 5-FU based chemotherapy after R0 resection. Int J Cancer 131: 505-511, 2012.

18. Gurzu S, Jung I, Sugimura H, Stefan-van Staden RI, Yamada H, Natsume H, Iwashita Y, Szodorai R and Szederjesi J: Maspin subcellular expression in wild-type and mutant TP53 gastric cancers. World J Gastrointest Oncol 15: 741-755, 2020.

19. Kanayama K, Imai H, Usugi E, Matsuda C, Ichishi M, Hirokawa YS and Watanabe M: Cancer-Related gene mutations and intratumoral genetic heterogeneity in human epidermal growth factor receptor 2 heterogeneous gastric cancer. Pathol Int 70: 865-870, 2020.

20. Grundei T, Vogelsang H, Ott K, Mueller J, Scholz M, Becker K, Fink U, Siewert JR, Höfler H and Keller G: Loss of heterozygosity and microsatellite instability as predictive markers for neoadjuvant treatment in gastric carcinoma. Clin Cancer Res 6: 4782-4788, 2000.

21. Chang SC, Lin JK, Lin TC and Liang WY: Loss of heterozygosity: An independent prognostic factor of colorectal cancer. World J Gastroenterol 11: 778784, 2005.

22. Lin X, Zhao Y, Song WM and Zhang B: Molecular classification and prediction in gastric cancer. Comput Struct Biotechnol J 13: 448-458, 2015.

23. Du X, Chen Z, Li W, Tan Y, Lu J, Zhu X, Zhao T, Dong G and Zeng L: Development of novel microsatellite DNA markers by cross-amplification and analysis of genetic variation in gerbils. J Hered 101: 710-716, 2010.

24. Plevová P: An update on inherited colon cancer and gastrointestinal polyposis. Klin Onkol 32: 97-108, 2019.

25. Yamamoto $\mathrm{H}$ and Imai K: Microsatellite instability: An update. Arch Toxicol 89: 899-921, 2015.

26. Wu WK, Cho CH, Lee CW, Fan D, Wu K, Yu J and Sung JJ: Dysregulation of cellular signaling in gastric cancer. Cancer Lett 28: 144-153, 2010. 
27. Yan LH, Wei WY, Xie YB and Xiao Q: New insights into the functions and localization of the homeotic gene CDX2 in gastric cancer. World J Gastroenterol 14: 3960-3966, 2014.

28. Xanthoulis A and Tiniakos DG: E2F transcription factors and digestive system malignancies: How much do we know? World J Gastroenterol 19: 3189-3198, 2013.

29. Hu H, Li C, Cai S, Zhu C, Tian Y, Zheng J, Hu J, Chen C and Liu W: Increased expression of pleiotrophin is a prognostic marker for patients with gastric cancer. Hepatogastroenterology 61: 1478-1482, 2014.

30. Hu H, Song Z, Yao Q, Geng X, Jiang L, Guo C and Li H: Proline-Rich protein 11 regulates self-renewal and tumorigenicity of gastric cancer stem cells. Cell Physiol Biochem 47: 1721-1728, 2018

31. Lotem J, Levanon D, Negreanu V, Bauer O, Hantisteanu S, Dicken $\mathbf{J}$ and Groner Y: Runx3 in immunity, inflammation and cancer. Adv Exp Med Biol 962: 369-393, 2017.

32. Huo X, Zhang S, Li Z, Gao J, Wang C, Li C, Guo M, Du X and Chen Z: Analysis ofthe relationship between microsatellite instability and thymic lymphoma induced by methyl-N-nitrosourea in C57BL/6J mice. Mut Res 771: 21-28, 2015.

33. Fujimoto A, Fujita M, Hasegawa T, Wong JH, Maejima K, Oku-Sasaki A,Nakano K, Shiraishi Y,MiyanoS, Yamamoto G, et al: Comprehensive analysis of indels in whole-genome microsatellite regions and microsatellite instability across 21 cancer types. Genome Res 24: 334-346, 2020

34. Huang KH, Chen MH, Fang WL, Lin CH, Chao Y, Lo SS, Li AF, Wu CW and Shyr YM: The clinicopathological characteristics and genetic alterations of signet-ring cell carcinoma in gastric cancer. Cancers (Basel) 17: 2318, 2020

35. Marrelli D, Polom K, Pascale V, Vindigni C, Piagnerelli R, De Franco L, Ferrara F, Roviello G, Garosi L, Petrioli R and Roviello F: Strong prognostic value of microsatellite instability in intestinal type non-cardia gastric cancer. Ann Surg Oncol 23: 943-950, 2016

36. Angell HK, Lee J, Kim KM, Kim K, Kim ST, Park SH, Kang WK Sharpe A, Ogden J and Davenport A: PD-L1 and immune infiltrates are differentially expressed in distinct subgroups of gastric cancer. Oncoimmunology 8: e1544442, 2018

37. Choi YY, Bae JM, An JY, Kwon IG, Cho I, Shin HB, Eiji T, Aburahmah M, Kim HI, Cheong JH, et al: Is microsatellite instability a prognostic marker in gastric cancer? A systematic review with meta-analysis. J Surg Oncol 110: 129-135, 2014.

38. Falchetti M, Saieva C, Lupi R, Masala G, Rizzolo P, Zanna I, Ceccarelli K, Sera F, Mariani-Costantini R, Nesi G, et al: Gastric cancer with high-level microsatellite instability: Target gene mutations, clinicopathologic features, and long-term survival. Hum Pathol 39: 925-932, 2008.

39. Hayden JD, Cawkwell L, Quirke P, Dixon MF, Goldstone AR, Sue-Ling H, Johnston D and Martin IG: Prognostic significance of microsatellite instability in patients with gastric carcinoma. Eur J Cancer 33: 2342-2346, 1997.

40. Wu MS, Lee CW, Sheu JC, Shun CT, Wang HP, Hong RL, Lee WJ and Lin JT: Alterations of BAT-26 identify a subset of gastric cancer with distinct clinicopathologic features and better postoperative prognosis. Hepatogastroenterology 49: 285-289, 2002.
41. Corso G, Velho S, Paredes J, Pedrazzani C, Martins D, Milanezi F, Pascale V, Vindigni C, Pinheiro H, Leite M, et al: Oncogenic mutations in gastric cancer with microsatellite instability. Eur J Cancer 47: 443-451, 2011.

42. Leite M, Corso G, Sousa S, Milanezi F, Afonso LP, Henrique R, Soares JM, Castedo S, Carneiro F, Roviello F, et al: MSI phenotype and MMR alterations in familial and sporadic gastric cancer. Int J Cancer 128: 1606-1613, 2011.

43. Maruvka YE, Mouw KW, Karlic R, Parasuraman P, Kamburov A, Polak P, Haradhvala NJ, Hess JM, Rheinbay E, Brody Y, et al: Analysis of somatic microsatellite indels identifies driver events in human tumors. Nat Biotechnol 35: 951-959, 2017.

44. Kim DG, An JY, Kim H, Shin SJ, Choi S, Seo WJ, Roh CK, Cho M, Son T, Kim HI, et al: Clinical implications of microsatellite instability in early gastric cancer. J Gastric Cancer 19: 427-437, 2019

45. Kim JY, Shin NR, Kim A, Lee HJ, Park WY, Kim JY, Lee CH, Huh GY and Park DY: Microsatellite instability status in gastric cancer: A reappraisal of its clinical significance and relationship with mucin phenotypes. Korean J Pathol 47: 28-35, 2013.

46. Lin JT, Wu MS, Shun CT, Lee WJ, Wang JT, Wang TH and Sheu JC: Microsatellite instability in gastric carcinoma with special references to histopathology and cancer stages. Eur J Cancer 31A: 1879-1882, 1995.

47. Suraweera N, Duval A, Reperant M, Vaury C, Furlan D, Leroy K, Seruca R, Iacopetta B and Hamelin R: Evaluation of tumor microsatellite instability using five quasimonomorphic mononucleotide repeats and pentaplex PCR. Gastroenterology 123: 1804-1811, 2002

48. Huo X, Xiao X, Zhang S, Zhou D and Chen Z: Association of intron microsatellite instability and exon mutational profile of TP53 in human gastric cancers. Anticancer Res 37: 4507-4514, 2017.

49. Liu X, Feng D, Huo X, Xiao X and Chen Z: Association of intron microsatellite status and exon mutational profiles of TP53 in human colorectal cancer. Exp Ther Med 18: 4287-4294, 2019.

50. Polom K, Marano L, Marrelli D, De Luca R, Roviello G, Savelli V, Tan P and Roviello F: Meta-Analysis of microsatellite instability in relation to clinicopathological characteristics and overall survival in gastric cancer. Br J Surg 105: 159-167, 2018.

51. An JY, Min JS, Lee YJ, Jeong SH, Hur H, Han SU, Hyung WJ, Cho GS, Jeong GA, Jeong O, et al: Safety of laparoscopic sentinel basin dissection in patients with gastric cancer: An analysis from the SENORITA prospective multicenter quality control trial. J Gastric Cancer 18: 30-36, 2018.

52. Choi J, Nam SK, Park DJ, Kim HW, Kim HH, Kim WH and Lee HS: Correlation between microsatellite instability-high phenotype and occult lymph node metastasis in gastric carcinoma. APMIS 123: 215-222, 2015.

This work is licensed under a Creative Commons Attribution-NonCommercial-NoDerivatives 4.0 International (CC BY-NC-ND 4.0) License. 